\title{
A missense mutation causes aspartase deficiency in Yersinia pestis
}

\begin{abstract}
Correspondence
Robert R. Brubaker

t-rbruba@bsd.uchicago.edu
\end{abstract}

Received 2 December 2007

Revised 6 February 2008

Accepted 6 February 2008
Ronald E. Viola, ${ }^{1}$ Lyudmyla Yerman, ${ }^{1}$ Janet M. Fowler, ${ }^{2}$ Cindy G. Arvidson ${ }^{2}$ and Robert R. Brubaker ${ }^{3}$

\author{
${ }^{1}$ Department of Chemistry, University of Toledo, 2801 W. Bancroft Street, Toledo, OH 43606, USA \\ ${ }^{2}$ Department of Microbiology and Molecular Genetics, Michigan State University, 2215 Biomedical \\ Physical Sciences, East Lansing, MI 48824, USA \\ ${ }^{3}$ Department of Microbiology, The University of Chicago, 920 E. 58th Street, Chicago, IL 60637, \\ USA
}

It is established that cells of Yersinia pestis, the causative agent of bubonic plague, excrete L-aspartic acid at the expense of exogenous L-glutamic acid during expression of the low-calcium response. Results of enzymic analysis provided here suggest that a previously defined deficiency of aspartase (AspA) accounts for this phenomenon rather than an elevated oxaloacetate pool. The only known distinction between most sequenced isolates of aspA from $Y$. pestis and the active gene in Yersinia pseudotuberculosis (the immediate progenitor of $Y$. pestis) is a single base transversion ( $\mathrm{G} \cdot \mathrm{C} \longrightarrow \mathrm{T} \cdot \mathrm{A}$ ) causing replacement of leucine (encoded by UUG) for valine (encoded by GUG) at amino acid position 363. The gene from $Y$. pestis KIM possesses a unique second transversion $(\mathrm{G} \cdot \mathrm{C} \longrightarrow \mathrm{T} \cdot \mathrm{A}$ ) at amino acid 146 causing substitution of aspartic acid (encoded by GAU) with tyrosine (encoded by UAU). We show in this study that $Y$. pestis expresses aspA as cross-reacting immunological material (CRIM). Functional and inactive aspA of $Y$. pseudotuberculosis PB1 and $Y$. pestis KIM, respectively, were then cloned and expressed in AspA-deficient Escherichia coli. After purification to near homogeneity, the products were subjected to biochemical analysis and found to exhibit similar secondary, tertiary and quaternary (tetrameric) structures as well as comparable Michaelis constants for L-aspartic acid. However, the $k_{\text {cat }}$ of the $Y$. pestis CRIM of strain KIM is only about $0.1 \%$ of that determined for the active AspA of $Y$. pseudotuberculosis. Return of valine for leucine at position 363 of the $Y$. pestis enzyme restored normal turnover $\left(k_{\text {cat }} 86 \pm 2 \mathrm{~s}^{-1}\right.$ ) provided that the amino acid substitution at position 146 was also reversed. These observations have important implications for understanding the nature of the stringent low-calcium response of $Y$. pestis and its role in promoting acute disease.

\section{INTRODUCTION}

Bubonic plague caused by Yersinia pestis has killed over 200 million people during the course of history and is thus the most devastating acute infectious disease known to man. Nevertheless, the molecular basis of its extraordinary virulence and broad host range remains uncertain. It is established, however, that the plague bacillus diverged from the enteropathogenic Yersinia pseudotuberculosis within the last 20000 years (Achtman et al., 1999), implying that high lethality reflects only a few genetic changes. Comparison of the annotated genomes of $Y$. pestis (Chain et al., 2006; Deng et al., 2002; Parkhill et al., 2001; Zhou et al., 2004) and Y. pseudotuberculosis (Chain et al., 2004) verified and

Abbreviations: $\mathrm{CD}$, circular dichroism; CRIM, cross-reacting immunological material; DLS, dynamic light scattering; ESI-MS, electrospray ionization mass spectrometry; LCR, low-calcium response; TCA, tricarboxylic acid cycle; T3SS, type III secretion system. extended earlier studies showing that cells of $Y$. pestis have both gained new functions and lost important features of Y. pseudotuberculosis (Brubaker, 1991; Perry \& Fetherston, 1997). Salient new genes were acquired by lateral transfer of two unique plasmids (Ferber \& Brubaker, 1981). These are the $\sim 10 \mathrm{~kb}$ pPCP encoding a plasminogen activator accounting for the low subcutaneous $\mathrm{LD}_{50}$ ( $<10$ cells) of Y. pestis in mice (Brubaker et al., 1965; Sodeinde et al., 1992 ) and the $\sim 100 \mathrm{~kb}$ pMT, which carries structural genes for capsular antigen fraction 1 and murine toxin (Kutyrev et al., 1986). Loss mutations include conversion of yadA and $y l p A$ encoded by the shared $\sim 70 \mathrm{~kb}$ low-calcium response (LCR) plasmid (termed pCD in Y. pestis and pYV in Y. pseudotuberculosis) into pseudogenes in Y. pestis ( $\mathrm{Hu}$ et al., 1998; Rosqvist et al., 1988). The LCR phenotype of $Y$. pestis is more stringent than that of Y. pseudotuberculosis (Brubaker, 2007) and is defined as the ability to either promote abrupt bacteriostasis in $\mathrm{Ca}^{2+}$-deficient medium 
at $37{ }^{\circ} \mathrm{C}$ accompanied by upregulation of a $\mathrm{pCD} / \mathrm{pYV}$ encoded type 3 secretion system (T3SS) or maintain vegetative growth with added $\mathrm{Ca}^{2+}$ while downregulating the T3SS $\left(\mathrm{Lct}^{+}\right.$) (Brubaker, 2007). The chromosome of $Y$. pestis contains large inversions, transpositions, and numerous small deletions and additions relative to its $Y$. pseudotuberculosis progenitor. These changes, as well as acquisition by $Y$. pestis of over 70 IS insertions (Chain et al., 2006; Deng et al., 2002; Parkhill et al., 2001; Zhou et al., 2004), have resulted in loss of about $13 \%$ of all functional genes of $Y$. pseudotuberculosis (Chain et al., 2004). A few of these mutations, especially those associated with downregulation of inflammation, are almost certainly associated with acute disease (Kawahara et al., 2002; Kukkonen et al., 2004). The remaining missing genes are largely regulatory in nature or encode metabolic functions; their elimination accounts for the established nutritional requirements of $Y$. pestis (Chain et al., 2004).

Chromosomal annotation did not provide obvious explanations for the loss in $Y$. pestis of detectable glucose-6phosphate dehydrogenase (Zwf) (Mortlock, 1962; Mortlock \& Brubaker, 1962) and aspartate ammonia-lyase or aspartase (AspA) (Brubaker, 2005, 2007; Dreyfus \& Brubaker, 1978). $\mathrm{Zwf}$ is required for synthesis of pentose from hexose and its absence may account for a temperature-dependent toxic effect of glucose on $\mathrm{Lcr}^{+} Y$. pestis (Brownlow \& Wessman, 1960). AspA activity catalyses the deamination of L-aspartate to form fumarate, a component of the tricarboxylic acid (TCA) cycle; thus its absence prevents catabolism of Laspartate (and metabolically related amino acids) via this efficient bioenergetic mechanism. Indeed, the LCR of $Y$. pestis is accompanied by excretion of L-aspartic acid at the expense of exogenous L-glutamate, causing a loss of metabolic carbon that otherwise would be conserved as oxaloacetate (Brubaker, 2005, 2007). Regeneration of lost oxaloacetate via phosphoenolpyruvate carboxykinase and phosphoenolpyruvate carboxylase (Baugh et al., 1964) accounts for the stimulatory effect of $\mathrm{CO}_{2}$ on growth of $Y$. pestis (Delwiche et al., 1959; Surgalla et al., 1964).

Further comparison of $z w f$ and aspA of $Y$. pseudotuberculosis and $Y$. pestis revealed putative missense mutations in the latter (Chain et al., 2004). For example, proline replaces serine at amino acid position 158 in the inactive Zwf of $Y$. pestis; this change is caused by a single base transition $(\mathrm{T} \cdot \mathrm{A} \rightarrow \mathrm{C} \cdot \mathrm{G})$. Similarly, a single base transversion $(\mathrm{G} \cdot \mathrm{C} \rightarrow \mathrm{T} \cdot \mathrm{A})$ at amino acid position 363 of AspA causes exchange of valine in the active enzyme of $Y$. pseudotuberculosis for leucine in Y. pestis (Chain et al., 2004, 2006; Deng et al., 2002; Parkhill et al., 2001; Zhou et al., 2004). While no other substitutions occur in Zwf, Y. pestis strain KIM (used in this study) also possesses a unique second base transversion $(\mathrm{G} \cdot \mathrm{C} \rightarrow \mathrm{T} \cdot \mathrm{A})$ at position 146 of AspA, causing replacement of aspartate by tyrosine (Deng et al., 2002) (Fig. 1). The substitution at position 146 was not reported for other yersiniae, including strains of $Y$. pseudotuberculosis.
Substitution of proline for other amino acids significantly alters the tertiary structure of many proteins and this effect may account for loss of Zwf activity in Y. pestis. However, loss of AspA accompanied by secretion of L-aspartate by conservative replacement of leucine for valine seemed unlikely. Alternative explanations for accumulation of Laspartate include the possibility of an increase in the oxaloacetate pool, favouring its transamination and release. It is significant in this context that the major chaperone GroEL, required for T3SS activity, is the only chromosomally encoded protein known to be produced during expression of the LCR by $Y$. pestis (Mehigh \& Brubaker, 1993). This heat-shock protein is also essential for the biological activity of citrate synthase (Grallert et al., 1998); thus T3SS-dependent depletion of GroEL could cause accumulation of oxaloacetate and its subsequent transamination and excretion as L-aspartate. Other obvious alternatives exist, although a block in transcription of asp $A$ seems unlikely as judged by its evident normal expression as determined by microarray analysis (Motin et al., 2004). The aims of this study were to demonstrate that AspA is expressed as cross-reacting immunological material (CRIM) in $Y$. pestis and to determine if the conserved single $\mathrm{G} \cdot \mathrm{C} \longrightarrow \mathrm{T} \cdot \mathrm{A}$ transversion at amino acid position 363 of AspA accounts for loss of enzymic activity.

\section{METHODS}

Bacterial strains and cultivation. Yersiniae used in this study were the type strains Y. pseudotuberculosis PB1 (Burrows \& Bacon, 1960) of serogroup 1b (Thal \& Knapp, 1971) and Y. pestis KIM (Finegold et al., 1968) of the Medievalis biovar (Devignat, 1951). Avirulent $\mathrm{Lcr}^{-}$ mutants of both species were selected on magnesium oxalate agar (Higuchi \& Smith, 1961) and a mutant of Y. pestis KIM lacking the $\sim 100 \mathrm{~kb}$ pigmentation sequence was isolated on Congo red agar (Surgalla \& Beesley, 1969). Transformed cells of Escherichia coli JRG1476 ( aspA) were used to prepare the aspA products of $Y$. pestis and $Y$. pseudotuberculosis. The chemically defined medium employed previously for microarray analysis (Motin et al., 2004) and definition of the LCR (Brubaker, 2005; Fowler \& Brubaker, 1994) was used to cultivate yersiniae for enzyme analysis. Conditions of growth, modifications of the medium that induce bacteriostasis versus steady-state growth, and preparation of the variations used in this study have been described in detail (Brubaker, 2007). The medium used in these experiments contained L-glutamate $(25 \mathrm{mM})$ and $\mathrm{Na}^{+}$ $(100 \mathrm{mM})$ in the presence $(4.0 \mathrm{mM})$ and absence of added $\mathrm{Ca}^{2+}$. E. coli JRG1476 was grown in Luria broth with kanamycin (100 $\mu \mathrm{g}$ $\mathrm{ml}^{-1}$ ) for preparation of cloned aspA products as defined below.

Enzyme analysis. $\mathrm{Lcr}^{+}$and $\mathrm{Lcr}^{-}$yersiniae were cultivated in chemically defined medium (Brubaker, 2007), harvested by centrifugation at $4{ }^{\circ} \mathrm{C}(10000 \mathrm{~g}$ for $30 \mathrm{~min})$, suspended and washed twice by similar centrifugation in cold $0.033 \mathrm{M}$ potassium phosphate buffer, $\mathrm{pH} 7.0$, brought to an $\mathrm{OD}_{620}$ of $\sim 400$ in $0.05 \mathrm{M}$ Tris/ $\mathrm{HCl}$ buffer, $\mathrm{pH} 7.8$, and disrupted by passage through a French pressure cell. The resulting preparation was again centrifuged as described and the cellfree extract carefully removed with a pipette, passed through a $0.22 \mu \mathrm{m}$ low-protein-binding filter (Millipore), and dialysed overnight against $0.01 \mathrm{M}$ Tris/ $\mathrm{HCl}$ buffer, $\mathrm{pH} 7.8$, containing DTT $(1.0 \mathrm{mM})$. The resulting cell-free extracts were used immediately for enzymic analysis. In all cases, protein concentration was determined by the Lowry method. 
1 MSNNIRIEED LLGTREVPAE AYYGVHTLRA IENFYISNSK ISDVPEFVRG MVMVKKAAAM ANKELHTIPR KIADIIIQAC DEVLDKGKCM DQFPVDVFQG MSNNIRIEED LLGTREVPAE AYYGVHTLRA IENFYISNSK ISDVPEFVRG MVMVKKAAAM ANKELHTIPR KIADIIIQAC DEVLDKGKCM DQFPVDVFQG MSNNIRIEED LLGTREVPAE AYYGVHTLRA IENFYISNSK ISDVPEFVRG MVMVKKAAAM ANKELHTIPR KIADIIIQAC DEVLDKGKCM DQFPVDVFQG MSNNIRIEED LIGTREVPAD AYYGVHTLRA IENFYISNNK ISDIPEFVRG MVMVKKAAAM ANKELQTIPK SVANAIIAAC DEVLNNGKCM DQFPVDVYOG MSNNIRIEED LLGTREVPAD AYYGVHTLRA IENFYISNNK ISDIPEFVRG MVMVKKAAAM ANKELQTIPK SVANAIIAAC DEVLNNGKCM DQFPVDVYQG

101 GAGTSLNMNT NEVLANIGLE LMGHQKGEYQ YLNPNDHLNK CQSTNDAYPT GERIAVYASI LKLIDAINQL GEGFGRKSKE FEKILKMGRT QLQDAVPMTL GAGTSLNMNT NEVLANIGLE LMGHQKGEYQ YLNPNDHLNK CQSTNYAYYPT GFRIAVYASI LKLIDAINQL GEGFGRKSKE FEKILKMGRT QLQDAVPMTI GAGTSLNMNT NEVLANIGLE LMGHQKGEYQ YLNPNDHLNK CQSTNDAYPT GERIAVYASI LKLIDAINQL GEGFGRKSKE FEKILKMGRT QLQDAVPMTL GAGTSVNMNT NEVLANIGLE LMGHQKGEYQ YLNFNDHVNK CQSTNDAYPT GERIAVYSSL IKLVDAINQL REGFERKAVE FQDILKMGRT QLQDAVPMTL GAGTSVNMNT NEVLANIGLE LMGHQKGEYQ YLNPNDHVNK CQSTNDAYPT GERIAVYSSL IKLVDAINQL REGFERKAVE FQDILKMGRT QLQDAVPMTL

201 GQEFRAFQVL LNEETKNLQR TAELLLEVNL GATAIGTALN TPEGYSQLAV QKLAEISGLA CVPAEDLIEA TSDCGAYVMV HSALKRLAVK MSKICNDLRL GQEFRAFQVL LNEETKNLQR TAELLLEVNL GATAIGTALN TPEGYSQLAV OKLAEISGLA CVPAEDLIEA TSDCGAYVMV HSALKRLAVK MSKICNDLRL GQEFRAFQVL LNEETKNLQR TAELLLEVNL GATAIGTALN TPEGYSQLAV QKLAEISGLA CVPAEDLIEA TSDCGAYVMV FSALRRLAVK MSKICNDLRL GQEFRAFSIL LKEEVKNIQR TAELLLEVNL GATAIGTGLN TPKEYSPLAV KKLAEVTGFP CVPAEDLIEA TSDCGAYVMV HGALKRLAVK MSKICNDLRL GQEFRAFSIL LKEEVKNIQR TAELLLEVNL GATAIGTGLN TPKEYSPLAV KKLAEVTGFP CVPAEDLIEA TSDCGAYVMV HGALKRLAVK MSKICNDLRL

301 LSSGPRTGLN EINLPELQAG SSIMPAKVNP VIPEVVNQVC FKVIGNDTCI TMAAFAGQLQ LNVMMEPVIGQ AMFESTHILT NACYNLLEKC INGITANKEV LSSGPRTGLN EINLPELQAG SSIMPAKVNP VIPEVVNQVC FKVIGNDTCI TMAAEAGQLQ LNEMEPVIGQ AMFESIHILT NACYNLLEKC INGITANKEV LSSGPRTGLN EINLPELQAG SSIMPAKVNP VIPEVVNQVC FKVIGNDTCI TMAAEAGQLQ LNIMMEPVIGQ AMFESIHILT NACYNLLEKC INGITANKEV LSSGPRAGLN EINLPELQAG SSIMPAKVNP VVPEVVNQVC FKVIGNDTTV TMAAEAGQLQ LNVMMEPVIGQ AMFESVHILT NACYNLLEKC INGITANKEV LSSGPRAGLN EINLPELQAG SSIMPAKVNP VVPEVVNQVC FKVIGNDTTV TMAAEAGOLQ LNVMMEPVIGQ AMFESVHILT NACYNLLEKC INGITANKEV

CERYVFNSIG IVTYLNPFIG HHNGDIVGKI CAETGKNVRE VVLERGLLTE AELDDIFSVE NLMHPAYKAK RYTDENEQ Y. pseudotuberculosis IP32953 CERYVFNSIG IVTYLNPFIG HHNGDIVGKI CAETGKNVRE VVLERGLLTE AELDDIFSVE NLMHPAYKAK RYTDENEQ Y.pestis KIM CERYVFNSIG IVTYLNPFIG HHNGDIVGKI CAETGKNVRE VVLERGLLTE AELDDIFSVE NLMHPAYKAK RYTDENEQ Y.pestis CO92 CEGYVYNSIG IVTYLNPFIG HHNGDIVGKI CAETGKSVRE VVLERGLLTE AELDDIFSVQ NLMHPAYKAK RYTDESEQ E. coli K 12 CEGYVYNSIG IVTYLNPFIG HHNGDIVGKI CAETGKSVRE VVLERGLLTE AELDDIFSVQ NLMHPAYKAK RYTDESEQ E. coli O157:H7 $\mathbf{t}$

Fig. 1. Sequence alignment of AspA from Y. pestis (Deng et al., 2002; Parkhill et al., 2001), Y. pseudotuberculosis (Chain et al., 2004) and E. coli (Blattner et al., 1997; Hayashi et al., 2001). Mutations at positions 146 and 363 (underlined) are the only differences found between the yersiniae aspartases. In contrast, there are numerous conservative and non-conservative changes between the E. coli and yersiniae enzymes, including non-polar or polar amino acids replaced by charged residues ( $\mathbf{\uparrow}$ ), charged amino acids replaced by neutral residues $(\boldsymbol{\Delta})$, and reversals of positively and negatively charged groups $(\boldsymbol{})$.

AspA activity in these preparations was estimated by determining the L-aspartic acid-dependent release of $\mathrm{NH}_{4}^{+}$with Nessler's reagent as undertaken previously (Dreyfus \& Brubaker, 1978). The reaction mixture consisted of $250 \mu \mathrm{mol}$ Tris/ $\mathrm{HCl}$ buffer (pH 7.0), $5.0 \mu \mathrm{mol}$ $\mathrm{MgCl}_{2}$, and dialysed cell-free extract in a total volume of $4.5 \mathrm{ml}$. The assay was started by addition of $250 \mu \mathrm{mol}$ sodium L-aspartate in a volume of $0.5 \mathrm{ml}$, and samples of $0.5 \mathrm{ml}$ were removed at intervals and added to Eppendorf tubes containing $0.1 \mathrm{ml} 1.5 \mathrm{M}$ trichloroacetic acid. The tubes were then centrifuged at highest speed for $1 \mathrm{~min}$ in a Beckman II microfuge and $0.5 \mathrm{ml}$ clear supernatant fluid was carefully removed and added to a tube containing $8.5 \mathrm{ml}$ distilled water. These samples received $1.0 \mathrm{ml}$ Nessler's reagent and, after incubation for $10 \mathrm{~min}$, were assayed for asparaginase activity by measuring $A_{480}$ (Yellin \& Wriston, 1966). The resulting values were then evaluated against a standard curve, prepared immediately before each determination by assays using known concentrations of $\mathrm{NH}_{4} \mathrm{Cl}$ in samples of $10 \mathrm{ml}$ containing the same concentrations of trichloroacetic acid and Nessler's reagent that were used to prepare samples for spectrophotometric analysis. AspA activity in purified preparations was measured by monitoring the appearance of fumarate at $240 \mathrm{~nm}\left(\varepsilon=2.53 \mathrm{mM}^{-1} \mathrm{~cm}^{-1}\right)$ (Karsten et al., 1985) in an assay buffer consisting of HEPES, $\mathrm{pH} 8.0(50 \mathrm{mM})$, magnesium acetate $(10 \mathrm{mM})$ and L-aspartate $(20 \mathrm{mM})$. Enzyme units were defined as $\mu \mathrm{mol}$ product generated per minute. The kinetic parameters of the yersiniae aspartases were measured by varying the concentration of L-aspartate and fitting the data to the MichaelisMenten equation. Kinetic assays were performed on either a PerkinElmer Lambda-1 or a Cary $50 \mathrm{UV} /$ visible spectrophotometer at a constant temperature of $20^{\circ} \mathrm{C}$. Citrate synthase in crude extracts was measured by determining the oxaloacetate-dependent release of CoA from acetyl-CoA at $412 \mathrm{~nm}$ (Srere, 1969). L-Glutmate: oxaloacetate transaminase and L-glutamate dehydrogenase in these samples were determined as described previously (Dreyfus \& Brubaker, 1978).

Cloning, expression and purification of AspA. The aspA genes of yersiniae were PCR-amplified using the conserved primers CGA214 (5'-GAAGGTTCATATGTCAAATAACATTCG-3') and CGA215 (5' CCGAGAAAATGAACAATAAGCTTAATATTC-3'). CGA214 incorporates a NdeI site at the start codon and CGA215 incorporates a HindIII site at the stop codon of aspA (underlined) These enzymes were used to digest the products, which were ligated into the expression vector pET24a digested with the same enzymes. The resulting plasmids were transformed into the aspA-deficient $E$. coli JRG1476 (Guest et al., 1984). Mutagenic primers were obtained from Integrated DNA Technologies. AspA production was initiated during cultivation at $37{ }^{\circ} \mathrm{C}$ in a shaker bath by addition of $1 \mathrm{mM}$ IPTG, followed by incubation for an additional $5 \mathrm{~h}$ at $32^{\circ} \mathrm{C}$. Approximately $2.5 \mathrm{~g}$ of wet cell paste was harvested from each litre of growth medium. This material was then suspended in the purification buffer (50 mM potassium phosphate, $\mathrm{pH} 6.5$, with $1 \mathrm{mM}$ EDTA and $1 \mathrm{mM}$ DTT) and the organisms were disrupted by sonication. Soluble proteins were fractionated in purification buffer with a 0 to $1.0 \mathrm{M}$ sodium chloride gradient on successive anion-exchange Sepharose XL high-capacity and Source $30 \mathrm{Q}$ high-resolution chromatography columns (Amersham Bioscience). The same purification protocol was used for preparation of the cloned aspA products of both yersiniae. The overall yield of highly purified $(>95 \%)$ enzyme was about $50 \mathrm{mg}$ protein from each litre of growth medium. 
Analysis for cross-reacting immunological material (CRIM). Biologically active AspA from E. coli K-12 and Y. pseudotuberculosis $\mathrm{PB} 1$ and the inactive protein from $Y$. pestis were isolated essentially as outlined above and used to prepare polyclonal antiserum in rabbits. This process entailed use of the immunization regimen used previously for LcrV (Une \& Brubaker, 1984) except that adjuvant was omitted; generation of precipitating antibodies was verified by diffusion in agar against the purified proteins. Immunoblots were undertaken as described previously (Motin et al., 1994).

Site-directed mutagenesis. Mutations of aspA from Y. pseudotuberculosis and Y. pestis were constructed using the Quik-Change II Site Directed Mutagenesis kit (Stratagene) and confirmed by DNA sequencing ( $M W G$ ). A single base change is needed to alter the GUG codon (valine) to UUG (leucine) in order to obtain the V363L $Y$. pseudotuberculosis mutant. The $Y$. pestis L363V mutation also requires only this single base change and, in order to make the Y146D mutant of $Y$. pestis KIM, the UAU codon of tyrosine was changed to the GAU codon of aspartate. The Y146D/L363V Y. pestis double mutant incorporated both of these base changes. These mutants were expressed and purified by using the same protocol as described above for the native enzymes.

Quaternary structure determination. The purified yersiniae aspartases $\left(0.5-1.0 \mathrm{mg} \mathrm{ml}^{-1}\right.$ in the phosphate purification buffer) were studied by dynamic light scattering (DLS) (DynaPro Titan, Wyatt Technologies) at $20{ }^{\circ} \mathrm{C}$ and $4{ }^{\circ} \mathrm{C}$ to determine the average particle size in solution. Native gel electrophoresis was carried out in Tris/glycine buffer (25 mM Tris, pH 8, $200 \mathrm{mM}$ glycine) using 4$12 \%$ Bistris polyacrylamide gels (Invitrogen). Gel filtration studies were conducted on a Superdex 200 column in $50 \mathrm{mM}$ potassium phosphate, $\mathrm{pH} 6.5$, with $1 \mathrm{mM}$ EDTA and $1 \mathrm{mM}$ DTT.

Circular dichroism (CD) spectroscopy. To compare the tertiary structure of Y. pestis, Y. pseudotuberculosis and the mutant V363L aspartases, the purified enzymes were examined by CD spectroscopy (Cary 62DS spectrometer) over the range $190-260 \mathrm{~nm}$ at room temperature. The enzyme concentrations in these solutions were varied from 6 to $20 \mu \mathrm{M}$, and the spectra reported represent an average of five scans.

Mass spectrometry. The purified aspartases from $Y$. pestis and $Y$. pseudotuberculosis were examined on a Q-TOF2 electrospray ionization mass spectrometer (ESI-MS) to determine accurate molecular masses. Each enzyme form was dialysed into $10 \mathrm{mM}$ ammonium acetate buffer, $\mathrm{pH} 6.5$, and about $0.5 \mathrm{mg}$ of each protein was used for mass analysis.

\section{RESULTS}

\section{Comparative catabolism of L-glutamate}

As noted above, cells of $\mathrm{Lcr}^{+} Y$. pestis exhibit a stringent LCR characterized by prompt bacteriostasis and secretion of L-aspartate arising from exogenous L-glutamate. Results of enzymic analysis were consistent with normal transamination by $Y$. pestis and $Y$. pseudotuberculosis of $\mathrm{L}-$ glutamate by L-glutmate: oxaloacetate transaminase with a catalytic amount of oxaloacetate (derived from 2-oxoglutarate via the TCA) to form L-aspartate (Table 1). The latter, however, was evidently unable to regenerate oxaloacetate in $Y$. pestis by recycling into the TCA as judged by the observed loss of AspA activity. The presence of similar levels of citrate synthase activity in both yersiniae suggests that a limitation of this enzyme in $Y$. pestis does not promote accumulation of oxaloacetate and its attendant conversion to L-aspartate. Finally, no significant differences were detected between the yersiniae in the activity of (primarily anabolic) L-glutamate dehydrogenase. The specific activity of these enzymes was not significantly influenced by $\mathrm{Ca}^{2+}$. Considered together, these findings indicate that the reported secretion of L-aspartate during the LCR is consistent with the observed deficiency of AspA activity in $Y$. pestis.

\section{Translation of aspA in Y. pestis}

Results of prior microarray analysis indicated that aspA undergoes normal transcription in Y. pestis (Motin et al., 2004); thus we considered the possibility that inactive AspA in this species reflects a lesion in translation. To examine this prospect, polyclonal rabbit antiserum was raised

Table 1. Specific activities of selected enzymes in $\mathrm{Lcr}^{+}$and $\mathrm{Lcr}^{-}$cells of $Y$. pestis $\mathrm{KIM}$ and $Y$. pseudotuberculosis PB1

The bacteria were cultivated at $37{ }^{\circ} \mathrm{C}$ in chemically defined medium with L-glutamate $(25 \mathrm{mM})$ and $\mathrm{Na}^{+}(100 \mathrm{mM})$ in the presence $(4.0 \mathrm{mM})$ and absence of added $\mathrm{Ca}^{2+}$. See Methods for details of enzyme assays and units.

\begin{tabular}{|c|c|c|c|c|c|}
\hline \multirow[t]{2}{*}{ Enzyme } & \multirow[t]{2}{*}{ Added $\mathrm{Ca}^{2+}$} & \multicolumn{2}{|c|}{ Y. pestis } & \multicolumn{2}{|c|}{ Y. pseudotuberculosis } \\
\hline & & $\mathrm{pCD}^{+}$ & $\mathrm{pCD}^{-}$ & $\mathrm{pYV}^{+}$ & $\mathrm{pYV}^{-}$ \\
\hline \multirow[t]{2}{*}{ L-Glutmate: oxaloacetate transaminase } & 0 & 0.074 & 0.089 & 0.085 & 0.087 \\
\hline & + & 0.116 & 0.079 & 0.086 & 0.072 \\
\hline \multirow[t]{2}{*}{ L-Glutamate dehydrogenase } & 0 & 0.033 & 0.030 & 0.027 & 0.026 \\
\hline & + & 0.033 & 0.028 & 0.024 & 0.020 \\
\hline \multirow[t]{2}{*}{ Citrate synthase } & 0 & 0.039 & 0.049 & 0.059 & 0.033 \\
\hline & + & 0.045 & 0.043 & 0.038 & 0.031 \\
\hline \multirow[t]{2}{*}{ Aspartase (L-aspartate ammonia-lyase) } & 0 & $<0.001$ & $<0.001$ & 0.075 & 0.050 \\
\hline & + & $<0.001$ & $<0.001$ & 0.060 & 0.044 \\
\hline
\end{tabular}


against highly purified AspA activity from $\mathrm{Lcr}^{-}$cells of $Y$. pseudotuberculosis. The resulting antiserum reacted in immunoblots with the homologous $\sim 50 \mathrm{kDa}$ peptide of $Y$. pseudotuberculosis, the corresponding material purified from $Y$. pestis, and crude extracts of $Y$. pestis, $Y$. pseudotuberculosis and E. coli (Fig. 2). A slight excess of the antiserum also eliminated $>99 \%$ of the enzymic activity of AspA from Y. pseudotuberculosis. These findings indicate that $Y$. pestis normally expresses defective AspA as a CRIM and suggest that one or both of the known changes in primary structure of the inactive enzyme (Y146D and L363V) accounts for loss of enzymic activity.

\section{Activities of AspA from Y. pseudotuberculosis versus the $Y$. pestis CRIM}

The specific activity of the purified cloned AspA of $Y$. pseudotuberculosis was 80 units $\mathrm{mg}^{-1}$ (Table 2), which is comparable to that of AspA from E. coli (Karsten et al., 1985). In contrast, the specific activity of the similarly

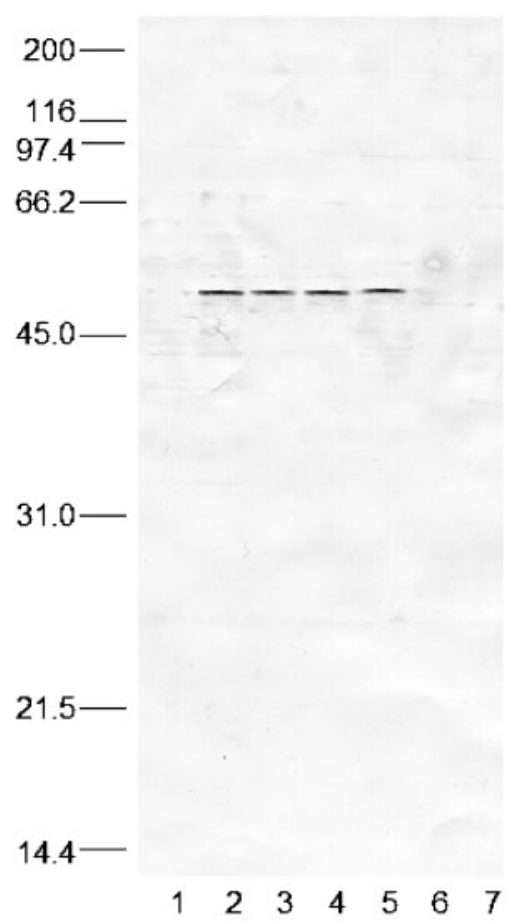

Fig. 2. Immunoblot prepared with rabbit polyclonal antiserum raised against highly purified AspA of $Y$. pseudotuberculosis PB1 after SDS-PAGE directed against phosphate-buffered saline (lanes 1, 7), AspA of $Y$. pseudotuberculosis $\left(1.0 \mu \mathrm{g} \mathrm{ml}^{-1}\right)$ used for immunization (lane 2), similarly prepared AspA (CRIM) of $Y$. pestis KIM (lane 3$)$, crude cell-free extract $\left(10 \mu \mathrm{g} \mathrm{ml}^{-1}\right)$ of $Y$. pseudotuberculosis PB1 (lane 4), crude cell-free extract $(10 \mu \mathrm{g}$ $\left.\mathrm{ml}^{-1}\right)$ of $Y$. pestis KIM (lane 5), and crude cell-free extract $(10 \mu \mathrm{g}$ $\mathrm{ml}^{-1}$ ) of $Y$. pestis $\mathrm{KIM}$ after absorption with excess anti-AspA serum (1 mg $\gamma$-globulin) (lane 6). Positions of size standards ( $k D a)$ are shown on the left. prepared CRIM of $Y$. pestis was more than 300 -fold lower $\left(0.2\right.$ units $\left.\mathrm{mg}^{-1}\right)$. The catalytic rates of the $Y$. pestis and $Y$. pseudotuberculosis enzymes were measured at varying concentrations of $\mathrm{L}$-aspartate to assess whether this reduction was a consequence of changes in substrate recognition. The $K_{\mathrm{m}}$ for L-aspartate was comparable between these two enzyme forms, but the $k_{\text {cat }}$ of the $Y$. pestis CRIM was significantly reduced (Table 2). To establish the importance of position 363 , a mutant of the $Y$. pseudotuberculosis AspA was constructed where valine was replaced by leucine to mimic the nearly inactive CRIM of $Y$. pestis. The latter was purified, kinetically characterized, and found to have a low specific activity of 0.2 units $\mathrm{mg}^{-1}$ similar to that of the Y. pestis AspA. Accordingly, the single conservative replacement of one aliphatic amino acid by another at position 363 was sufficient to dramatically attenuate catalytic activity without inducing gross structural changes.

\section{Consequences of missense mutations in AspA on specific activity}

Since conservative replacement of leucine for valine in the $Y$. pseudotuberculosis enzyme caused dramatic loss of catalytic activity, full recovery was anticipated upon substitution of valine for leucine in the CRIM of $Y$. pestis. This L363V variant was constructed, expressed and purified but, surprisingly, showed the same low catalytic activity as the native $Y$. pestis AspA (Table 2). As previously noted, the only other difference between the enzyme from $Y$. pseudotuberculosis $\mathrm{PB} 1$ and $Y$. pestis KIM is a nonconservative replacement in the latter of tyrosine for aspartic acid at position 146, although aspartic acid occupies this position in other yersiniae, including $Y$. pestis CO92 (Parkhill et al., 2001). A Y146D variant of the $Y$. pestis KIM AspA was prepared and characterized but this replacement similarly failed to enhance catalysis (Table 2). Since neither of these single reversions alone resulted in significant recovery of enzymic activity, either one or the other forward mutation is evidently sufficient to cause the observed inhibition. To verify this assumption, a double Y146D/L363V mutant possessing an amino acid sequence identical to that of the fully active $Y$. pseudotuberculosis enzyme was prepared and subjected to enzymic analysis. These two changes resulted in an enzyme form with high specific activity (72 units $\mathrm{mg}^{-1}$ ) and kinetic parameters that were indistinguishable from the native Y. pseudotuberculosis AspA (Table 2).

\section{Structural comparison of AspA from Y. pseudotuberculosis and the Y. pestis CRIM}

The similar $K_{\mathrm{m}}$ for L-aspartic acid suggested that the primary structure responsible for substrate recognition and binding was not affected by the Y146D and L363V substitutions but that these mutations alter the positioning of catalytic residues at the active site, thereby causing a loss of activity. By analogy with the well-established tetrameric 
Table 2. Kinetic parameters of L-aspartases from $Y$. pestis $\mathrm{KIM}$ and $Y$. pseudotuberculosis PB1

\begin{tabular}{|lccccc|}
\hline Source & Specific activity $\left(\mathbf{U ~ m g}^{-\mathbf{1}}\right)$ & $\boldsymbol{k}_{\mathrm{cat}}\left(\mathbf{s}^{-\mathbf{1}}\right)$ & $\boldsymbol{K}_{\mathbf{m}}(\mathbf{m M})$ & $\boldsymbol{k}_{\mathrm{cat}} / \boldsymbol{K}_{\mathbf{m}}\left(\mathbf{M}^{-\mathbf{1}} \mathbf{s}^{-\mathbf{1}}\right)$ & $\boldsymbol{k}_{\mathrm{cat}} / \mathbf{K}_{\mathbf{m}}(\%)$ \\
\hline Y. pseudotuberculosis & 80 & $87 \pm 4$ & $2.1 \pm 0.2$ & $41700 \pm 2600$ & 100 \\
Y. pestis & 0.2 & $0.10 \pm 0.06$ & $1.3 \pm 0.2$ & $80 \pm 7$ \\
L363V Y. pestis & 0.2 & $0.12 \pm 0.01$ & $1.5 \pm 0.2$ & $80 \pm 8$ & 0.2 \\
Y146D Y. pestis & 0.2 & $0.13 \pm 0.01$ & $1.3 \pm 0.2$ & $100 \pm 10$ & 0.2 \\
Y146D/L363V Y. pestis & 72 & $86 \pm 2$ & $1.2 \pm 0.1$ & $74000 \pm 3000$ \\
\hline
\end{tabular}

structure of E. coli AspA (Watanabe et al., 1981), the enzymes from yersiniae are also expected to exist as tetramers. However, because the active site of AspA is formed at the interface between subunits (Shi et al., 1997), any changes in subunit association as a consequence of these point mutations might alter the active site structure and therefore affect catalytic activity.

This possibility was investigated by analysis of the quaternary structure and subunit conformation of these enzyme forms. The average particle size of the AspA species was determined in solution at $20{ }^{\circ} \mathrm{C}$ and $4{ }^{\circ} \mathrm{C}$ by DLS. Both enzymes showed a similar peak via DLS at both temperatures, with a particle size predicting a molecular mass of $130 \pm 20 \mathrm{kDa}$. The actual molecular mass of the AspA subunit was $52 \mathrm{kDa}$, so the expected mass of the tetramer should be about $200 \mathrm{kDa}$. Mass prediction by DLS assumes that the protein has a spherical shape, whereas the structure of tetrameric E. coli AspA is quite elongated (Shi et al., 1997), so the value predicted by DLS deviates from the actual mass. To compensate for the errors in mass estimation due to this non-spherical shape, the well-characterized E. coli enzyme was compared and found to yield a predicted value of $135 \mathrm{kDa}$. Since the yersiniae enzymes have essentially the same particle size as the E. coli AspA, they likely also exist predominantly as tetramers in solution. This assumption was supported by gel filtration studies, in which a mixture of purified E. coli and yersiniae enzymes co-eluted from a Superdex 200 size- exclusion column. Native gel electrophoresis also showed bands at the same position as the E. coli AspA for each of the yersiniae enzymes, although some smearing was observed for the $Y$. pestis AspA (data not shown), suggesting partial equilibrium with a lower molecular mass component. These findings argue against the possibility that loss of activity reflects significant changes in subunit association.

AspA from $Y$. pseudotuberculosis and $Y$. pestis was also examined by CD spectroscopy over the wavelength range 190-260 $\mathrm{nm}$ to assess possible changes in secondary structure that could be responsible for the observed catalytic differences. The two native enzymes exhibited virtually identical spectra (Fig. 3), indicating similar overall folding and secondary structure. A nearly identical CD spectrum was also measured for the V363L mutant of $Y$. pseudotuberculosis aspartase. Therefore the mutations in primary structure found to cause dramatic differences in catalytic activity evidently do not promote significant changes in secondary structure. Samples of $Y$. pseudotuberculosis and $Y$. pestis AspA were also examined by mass spectrometry to identify potential covalent protein modifications at specific amino acids that could be capable of causing the observed changes in activity. The molecular mass of the CRIM from Y. pestis as determined by ESI-MS was 52526 Da compared to a calculated mass of 52536 Da; the corresponding value estimated for the AspA of $Y$. pseudotuberculosis was within $2 \mathrm{Da}$ of the calculated

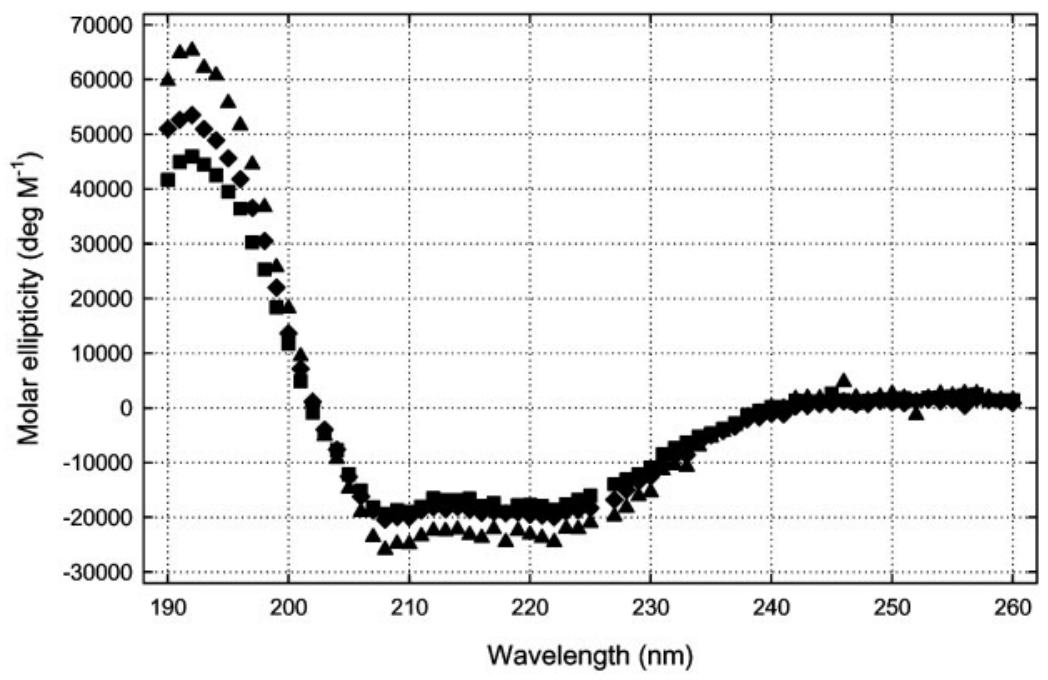

Fig. 3. CD spectra of the purified aspartases from $Y$. pseudotuberculosis PB1 ( $), Y$. pestis $\mathrm{KIM}(\boldsymbol{\square})$ and the V363L mutant of $Y$. pseudotuberculosis ( $\mathbf{\Delta})$. 
molecular mass of $52474 \mathrm{Da}$. These results indicate that covalent modifications do not account for the dramatic differences in catalytic activity observed between the two proteins.

\section{DISCUSSION}

\section{Sequence comparison of aspartases}

Although most mutational events causing loss of enzymic activity are readily identified by bioinformatics analysis, missense mutations are often overlooked because the investigator cannot distinguish between amino acid substitutions in silent regions and those occurring at critical positions such as the catalytic centre. Prior knowledge that a given function is defective may warrant the suggestion that a markedly dissimilar amino acid accounts for inactivity (as occurs upon replacement of proline for serine in Zwf of $Y$. pestis). However, conservative amino acid changes cannot, at present, be correlated with altered enzymic activity. The fully active AspA of $Y$. pseudotuberculosis emphasizes this phenomenon: its sequence differs from that of the E. coli enzyme at about 50 amino acid positions (Fig. 1). While many of these differences are conservative replacements, there are nine positions in which polar or non-polar amino acids are replaced by charged residues, an additional five positions where charged residues have been replaced by uncharged amino acids, and two positions where positively and negatively charged amino acids have been swapped. Despite these extensive changes, the kinetic parameters of the E. coli and $Y$. pseudotuberculosis aspartases are indistinguishable. As previously defined, the sequences of the L-aspartases from $Y$. pseudotuberculosis and $Y$. pestis are virtually identical (differing by only one or two amino acids) yet the Y. pestis enzyme is essentially inactive. This relationship suggests that the identity of the amino acids at these positions, Asp146 and Val363, must play significant roles in maintaining catalytic activity.

\section{Structural comparison of aspartases}

Several members within this ammonia-lyase family catalyse a deamination reaction that is related to that of aspartase, and they do so by a mechanism involving a dehydroalanine that is generated through modification of an active site serine (Langer et al., 1994; Schuster \& Rétey, 1995). However, no such modifications were observed by mass spectrometry in the yersiniae aspartases that could account for the observed differences in activity. While changes in the identity of the amino acids at these positions were shown to have a dramatic impact on the catalytic activity of aspartase, this effect is not caused by significant changes in the higherorder structure of the $Y$. pestis protein. CD spectra of the active and inactive forms of aspartase are nearly identical, indicating no substantial changes in secondary structure.
DLS and size-exclusion chromatography data are consistent with tetrameric structures for each enzyme form.

\section{Active site structure of L-aspartases}

We have examined the location of Asp146 and Val363 within the aspartase structure to gain a better understanding of their potential roles. The location of the active site of aspartase was previously determined by comparing the apoaspartase structure (Shi et al., 1997) with E. coli fumarase C (Weaver et al., 1995; Weaver \& Banaszak, 1996), a wellstudied enzyme from the same family that catalyses a similar reaction. There are four active sites in the tetramer of aspartase, with each active site found at the junction of sets of three out of the four subunits. For example, the putative active site residues of one such site in E. coli aspartase includes the proposed substrate-binding groups Lys 327 from subunit $\mathrm{C}$ and $\operatorname{Arg} 29$ from subunit A, along with the catalytic Ser143 from subunit A and an additional loop from subunit D (Fig. 4). Each of these active site amino acids is fully conserved throughout the entire aspartase family. Ser143 was proposed to function as a catalytic acid (Jayasekera et al., 1997), and a conservative substitution of Ser143 by threonine results in a dramatic loss of catalytic activity to $<2 \%$ that of native aspartase (Jayasekera \& Viola, 1999). However, the amino acid at position 363 is more than $10 \AA(1 \mathrm{~nm})$ away from the putative substrate-binding residues. Thus, there is a low possibility for changes at this

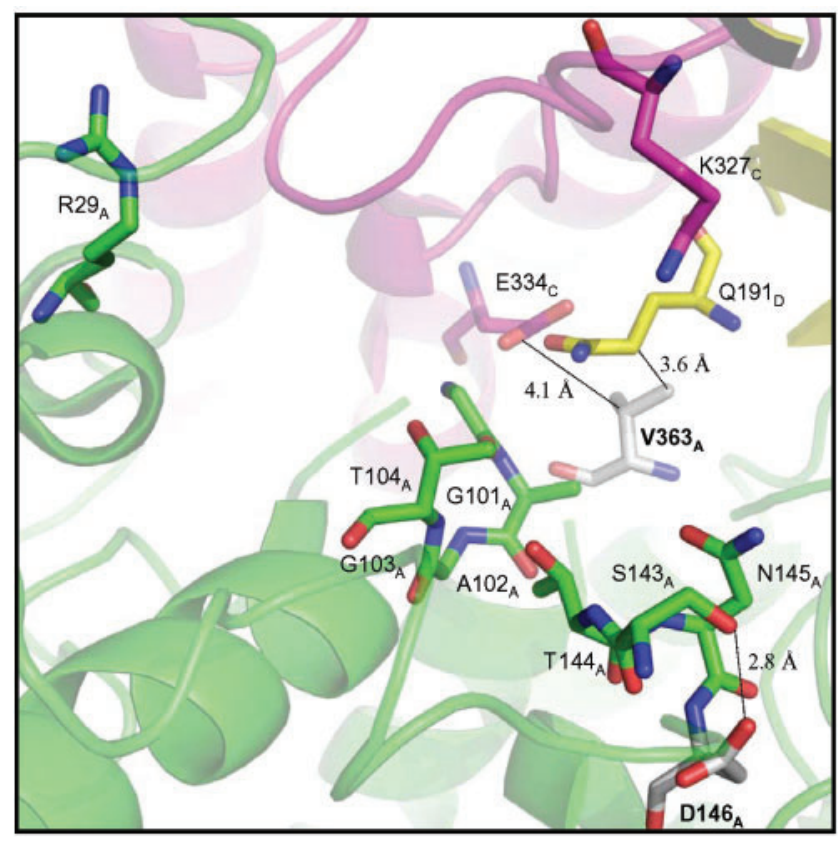

Fig. 4. Putative active site of aspartase from $E$. coli at the junction of subunits A (green), C (pink) and D (yellow) (Shi et al., 1997), with the mutation positions of amino acids from the $Y$. pestis KIM enzyme (in grey) and their proximity to functionally important amino acids in two adjacent subunits. 
position to affect substrate binding. This is consistent with the unaltered Michaelis constant for L-aspartate within the tested family of yersiniae enzymes (Table 2). The amino acid at the other varied position, Asp146, is situated adjacent to the putative catalytic amino acid, Ser143, with the aspartate carboxyl oxygen about $2.8 \AA(0.28 \mathrm{~nm})$ from the serine hydroxyl group (Fig. 4). This carboxylate group is involved in helping to position this serine for catalysis, along with Asn145. A non-conservative replacement of Asp146 would certainly disrupt the orientation of the serine side chain and diminish catalytic efficiency. However, as noted, a mutation leading to a tyrosine in position 146 is only observed in the $Y$. pestis KIM strain, while the other low-activity yersiniae isolates retain an aspartate at this position. Replacement of this tyrosine with an aspartic acid was not sufficient to recover enzymic activity, so other changes must also disrupt catalysis in the Y. pestis CRIM.

\section{Effect of mutations on catalytic activity}

Mutations at position 363 are found in all $Y$. pestis aspartases, and seem to be more directly correlated with diminished enzyme performance. Val363, present in the active E. coli and Y. pseudotuberculosis aspartases, is positioned at the bottom of the active site cleft (Fig. 4) and is $3.6-4.0 \AA(0.36-0.4 \mathrm{~nm})$ away from the closest contacts with Glu334 of subunit C and Gln191 of subunit D. The comparable amino acids in fumarase (Glu331 and His188) form a charge-relay pair that is proposed to activate a water molecule for proton abstraction from the L-malate substrate (Weaver \& Banaszak, 1996). However, this putative catalytic histidine of fumarase is a glutamine in the aspartases, a functional group that could not be involved in the proposed charge-relay system. Thus, the roles of these residues are not as well established for aspartases. The side chain of Val363 in the catalytically active E. coli and Y. pseudotuberculosis aspartases is small enough to avoid steric clashes with the side chains of Glu334 and Gln191. However, the enzymes with low catalytic activity each have larger residues at this position. Even the conservative mutation to a leucine with a slightly larger side chain volume in $Y$. pestis aspartase was found to have a great impact on catalytic activity. These observations suggest that mutations at position 363 indirectly inhibit enzyme activity, perhaps by causing the catalytic residues Glu334 and Gln191 to alter their positions, thus disrupting their contributions to catalysis.

\section{Excretion of L-aspartate}

The species-specific deficiency of AspA activity (Dreyfus \& Brubaker, 1978) and attendant secretion of L-aspartate by $\mathrm{Ca}^{2+}$-starved Y. pestis is well established (Brubaker, 2005, 2007). Nevertheless, only a casual relationship existed between these phenomena prior to this study, which detected no significant differences in major enzymes that influence the aspartate pool other than the AspA of Y. pseudotuberculosis and corresponding CRIM of $Y$. pestis. Additional work will be required to determine the reasons why secretion of $\mathrm{L}$-aspartate is limited to $\mathrm{Ca}^{2+}$-starved plague bacilli and why $\mathrm{Na}^{+}$ promotes the associated nutritional requirement for $\mathrm{Ca}^{2+}$ (Brubaker, 2007). Structural studies have begun, with the aim of verifying the proposed alterations in side chain positioning at the active site of aspartase. We are also examining the possibility that the loss of enzymic activity caused by these changes may promote acute disease. This prospect is in accord with the finding that the attenuated Microtis biovar of $Y$. pestis, known to remain virulent for the Muridiae but not humans (Fan et al., 1995), possesses the same functional aspA as does Y. pseudotuberculosis (Zhou et al., 2004).

\section{Concluding remarks}

In summary, these results indicate that the observed replacement of one aliphatic amino acid (leucine) for another (valine) in AspA of $Y$. pestis is hardly conservative and does indeed contribute to the loss of enzymic activity, resulting in major phenotypic changes that define the plague bacillus. Taken together, these findings strongly indicate that the missense mutation at amino acid position 363 accounts for loss of enzymic activity in Y. pestis AspA. Further study will be necessary to determine if the similar event at position 146 is limited to the KIM strain. In this context, isolates possessing only the missense mutation at position 363 could readily revert or suppress this mutation in one step, whereas two such events would be required to restore AspA activity in strain KIM.

\section{ACKNOWLEDGEMENTS}

This work was sponsored by the NIH/NIAID Regional Center of Excellence for Bio-defense and Emerging Infectious Diseases Research (RCE) Program. R. R. B. wishes to acknowledge membership within and support from the Region V 'Great Lakes' RCE (NIH award 1U54-AI-057153).

\section{REFERENCES}

Achtman, M., Zurth, K., Morelli, G., Torrea, G., Guiyoule, A. \& Carniel, E. (1999). Yersinia pestis, the cause of plague, is a recently emerged clone of Yersinia pseudotuberculosis. Proc Natl Acad Sci U S A 96, 14043-14048.

Baugh, C. L., Lanham, J. W. \& Surgalla, M. (1964). Effects of bicarbonate on growth of Pasteurella pestis. II. Carbon dioxide fixation into oxalacetate by cell-free extracts. J Bacteriol 88, 1394-1398.

Blattner, F. R., Plunkett, G., III, Bloch, C. A., Perna, N. T., Burland, V., Riley, M., Collado-Vides, J., Glasner, J. D., Rode, C. K. \& other authors (1997). The complete genome sequence of Escherichia coli K12. Science 277, 1453-1474.

Brownlow, W. J. \& Wessman, G. E. (1960). Nutrition of Pasteurella pestis in chemically defined media at temperatures of 36 to $38 \mathrm{C}$. J Bacteriol 79, 299-304.

Brubaker, R. R. (1991). Factors promoting acute and chronic diseases caused by yersiniae. Clin Microbiol Rev 4, 309-324.

Brubaker, R. R. (2005). Influence of $\mathrm{Na}^{+}$, dicarboxylic amino acids, and $\mathrm{pH}$ in modulating the low-calcium response of Yersinia pestis. Infect Immun 73, 4743-4752. 
Brubaker, R. R. (2007). Intermediary metabolism, $\mathrm{Na}^{+}$, the low calcium-response, and acute disease. In The Genus Yersinia: from Genomics to Function, pp. 116-129. Edited by R. D. Perry. New York: Springer.

Brubaker, R. R., Beesley, E. D. \& Surgalla, M. J. (1965). Pasteurella pestis: role of pesticin I and iron in experimental plague. Science 149, 422-424.

Burrows, T. W. \& Bacon, G. W. (1960). V and W antigens in strains of Pasteurella pseudotuberculosis. Br J Exp Pathol 41, 38-44.

Chain, P. S., Carniel, E., Larimer, F. W., Lamerdin, J., Stoutland, P. O., Regala, W. M., Georgescu, A. M., Vergez, L. M., Land, M. L. \& other authors (2004). Insights into the evolution of Yersinia pestis through whole-genome comparison with Yersinia pseudotuberculosis. Proc Natl Acad Sci U S A 101, 13826-13831.

Chain, P. S. G., Hu, P., Malfatti, S. A., Radnedge, L., Larimer, F., Vergez, L. M., Worsham, P., Chu, M. C. \& Andersen, G. L. (2006). Complete genome sequence of Yersinia pestis strains Antiqua and Nepal516: evidence of gene reduction in an emerging pathogen. J Bacteriol 188, 4453-4463.

Delwiche, E. A., Fukui, G. M., Andrews, A. W. \& Surgalla, M. J. (1959). Environmental conditions affecting the population dynamics and the retention of virulence of Pasteurella pestis: the role of carbon dioxide. J Bacteriol 77, 355-380.

Deng, W., Burland, V., Plunkett, G. I., III, Boutin, A., Mayhew, G. F., Liss, P., Perna, N. T., Rose, D. J., Mau, B. \& other authors (2002). Genome sequence of $Y$. pestis KIM. J Bacteriol 184, 4601-4611.

Devignat, R. (1951). Variétés de l'espèce Pasteurella pestis. Nouvelle hypothèse. Bull World Health Organ 4, 247-263.

Dreyfus, L. A. \& Brubaker, R. R. (1978). Consequences of aspartase deficiency in Yersinia pestis. J Bacteriol 136, 757-764.

Fan, Z., Luo, Y., Wang, S., Jin, L., Zhou, X., Liu, J., Zhang, Y. \& Li, F. (1995). Microtus brandti plague in the Xilin Gol Grassland was inoffensive to humans. Chin J Control Endemic Dis 10, 56-57 (in Chinese).

Ferber, D. M. \& Brubaker, R. R. (1981). Plasmids in Yersinia pestis. Infect Immun 31, 839-841.

Finegold, M. J., Petery, R. F., Berendt, R. F. \& Adams, H. R. (1968). Studies on the pathogenesis of plague. Blood coagulation and tissue responses of Macaca mulatta following exposure to aerosols of Pasteurella pestis. Am J Pathol 53, 99-114.

Fowler, J. M. \& Brubaker, R. R. (1994). Physiological basis of the low calcium response in Yersinia pestis. Infect Immun 62, 5234-5241.

Grallert, H., Rutkat, K. \& Buchner, J. (1998). GroEL traps dimeric and monomeric unfolding intermediates of citrate synthase. J Biol Chem 273, 33305-33310.

Guest, J. R., Roberts, R. E. \& Wilde, R. J. (1984). Cloning of the aspartase gene (aspA) of Escherichia coli. J Gen Microbiol 130, 1271-1278.

Hayashi, T., Makino, K., Ohnishi, M., Kurokawa, K., Ishii, K., Yokoyama, K., Han, C. G., Ohtsubo, E., Nakayama, K. \& other authors (2001). Complete genome sequence of enterohemorrhagic Escherichia coli $\mathrm{O} 157: \mathrm{H} 7$ and genomic comparison with a laboratory strain K-12. DNA Res 8, 11-22.

Higuchi, K. \& Smith, J. L. (1961). Studies on the nutrition and physiology of Pasteurella pestis: VI. A differential plating medium for the estimation of the mutation rate to avirulence. J Bacteriol 81, 605-608.

Hu, P., Elliott, J., McCready, P., Skowronski, E., Garnes, J., Kobayashi, A., Brubaker, R. R. \& Garcia, E. (1998). Structural organization of virulence-associated plasmids of Yersinia pestis. J Bacteriol 180, 5192-5202.

Jayasekera, M. M. \& Viola, R. E. (1999). Recovery of catalytic activity from an inactive aggregated mutant of L-aspartase. Biochem Biophys Res Commun 264, 596-600.
Jayasekera, M. M. K., Shi, W., Farber, G. K. \& Viola, R. E. (1997). Evaluation of functionally important amino acids in L-aspartate ammonia-lyase from Escherichia coli. Biochemistry 36, 9145-9150.

Karsten, W. E., Hunsley, J. R. \& Viola, R. E. (1985). Purification of aspartase and aspartokinase-homoserine dehydrogenase I from Escherichia coli by dye-ligand chromatography. Anal Biochem 147, 336-341.

Kawahara, K., Tsukano, H., Watanabe, H., Lindler, B. \& Matsuura, M. (2002). Modification of the structure and activity of lipid A in Yersinia pestis lipopolysaccharide by growth temperature. Infect Immun 70, 4092-4098.

Kukkonen, M., Suomalainen, M., Kyllonen, P., Lahteenmaki, K., Lang, H., Virkola, R., Helander, I., Holst, O. \& Korhonen, T. (2004). Lack of O-antigen is essential for plasminogen activation by Yersinia pestis and Salmonella enterica. Mol Microbiol 51, 215-225.

Kutyrev, V. V., Popov, Y. A. \& Protsenko, O. A. (1986). Pathogenicity plasmids of the plague microbe (Yersinia pestis). Mol Gen Mikrobiol Virusol 6, 3-11.

Langer, M., Reck, G., Reed, J. \& Rétey, J. (1994). Identification of serine-143 as the most likely precursor of dehydroalanine in the active site of histidine ammonia-lyase. A study of the overexpressed enzyme by site-directed mutagenesis. Biochemistry 33, 6462-6467.

Mehigh, R. J. \& Brubaker, R. R. (1993). Major stable peptides of Yersinia pestis synthesized during the low-calcium response. Infect Immun 61, 13-22.

Mortlock, R. P. (1962). Gluconate metabolism of Pasteurella pestis. $J$ Bacteriol 84, 53-59.

Mortlock, R. P. \& Brubaker, R. R. (1962). Glucose-6-phosphate dehydrogenase and 6-phosphogluconate dehydrogenase activities of Pasteurella pestis and Pasteurella pseudotuberculosis. J Bacteriol 84, 1122-1123.

Motin, V. L., Nakajima, R., Smirvov, G. B. \& Brubaker, R. R. (1994). Passive immunity to yersiniae mediated by anti-recombinant $\mathrm{V}$ antigen and protein $\mathrm{A}-\mathrm{V}$ antigen fusion peptide. Infect Immun 62, 4192-4201.

Motin, V. L., Georgescu, A. M., Fitch, J. P., Gu, P. P., Nelson, D. O., Mabery, S. L., Garnham, J. B., Sokhansanj, B. A., Ott, L. L. \& other authors (2004). Temporal global changes in gene expression during temperature transition in Yersinia pestis. J Bacteriol 186, 6298-6305.

Parkhill, J., Wren, B. W., Thomson, N. R., Titball, R. W., Holden, M. T., Prentice, M. B., Sebaihia, M., James, K. D., Churcher, C. \& other authors (2001). Genome sequence of Yersinia pestis, the causative agent of plague. Nature 413, 523-527.

Perry, R. D. \& Fetherston, J. D. (1997). Yersinia pestis - etiologic agent of plague. Clin Microbiol Rev 10, 35-66.

Rosqvist, R., Skurnik, M. \& Wolf-Watz, H. (1988). Increased virulence of Yersinia pseudotuberculosis by two independent mutations. Nature 334, 522-525.

Schuster, B. \& Rétey, J. (1995). The mechanism of action of phenylalanine ammonia-lyase: the role of prosthetic dehydroalanine. Proc Natl Acad Sci U S A 92, 8433-8437.

Shi, W. X., Dunbar, J. L., Jayasekera, M. M., Viola, R. E. \& Farber, G. K. (1997). The structure of L-aspartate ammonia-lyase from Escherichia coli. Biochemistry 36, 9136-9144.

Sodeinde, O. A., Subrahmanyam, Y. V. B. K., Stark, K., Quan, T., Bao, Y. \& Goguen, J. D. (1992). A surface protease and the invasive character of plague. Science 258, 1004-1007.

Srere, P. A. (1969). Citrate synthase. Methods Enzymol 13, 3-11. 
Surgalla, M. J. \& Beesley, E. D. (1969). Congo red-agar plating medium for detecting pigmentation in Pasteurella pestis. Appl Microbiol 18, 834-837.

Surgalla, M. J., Andrews, A. W. \& Baugh, C. L. (1964). Effects of bicarbonate on growth of Pasteurella pestis. I. Differential response of virulent and avirulent cells. J Bacteriol 88, 269-272.

Thal, E. \& Knapp, W. (1971). A revised antigenic scheme of Yersinia pseudotuberculosis. Symp Ser Immunobiol Stand 15, 219-222.

Une, T. \& Brubaker, R. R. (1984). Roles of V antigen in promoting virulence and immunity in yersiniae. J Immunol 133, 2226-2230.

Watanabe, Y., Iwakura, M., Tokushige, M. \& Eguchi, G. (1981). Studies on aspartase. VII. Subunit arrangement of Escherichia coli aspartase. Biochim Biophys Acta 661, 261-266.
Weaver, T. M. \& Banaszak, L. J. (1996). Crystallographic studies of the catalytic and a second site in fumarase C from Escherichia coli. Biochemistry 35, 13955-13965.

Weaver, T. M., Levitt, D. G., Donnelly, M. I., Wilkens-Stevens, P. P. \& Banaszak, L. J. (1995). The multisubunit active site of fumarase C from Escherichia coli. Nat Struct Biol 2, 654-662.

Yellin, T. O. \& Wriston, J. C. (1966). Purification and properties of guinea pig serum asparaginase. Biochemistry 5, 1605.

Zhou, D., Tong, Z., Song, Y., Han, Y., Pei, D., Pang, X., Zhai, J., Li, M., Cui, B. \& other authors (2004). Genetics of metabolic variations between Yersinia pestis biovars and the proposal of a new biovar, microtus. J Bacteriol 186, 5147-5152.

Edited by: J. Parkhill 